\title{
Urine Sampling and Culture in the Diagnosis of Urinary Tract Infection: A Review Article
}

Iddah M. Ali MSc, $\mathrm{PhD}^{1 *}$, Benard O. Wesonga ${ }^{2}$ ${ }^{\mathrm{T}}$ Department of Medical Microbiology and Parasitology, School of Medicine, Masinde Muliro University of Science and Technology,
P.O. Box 190-50100, Kakamega, Kenya
${ }^{2}$ Department of Community Health and Behavoural Sciences, School of Medicine, Masinde Muliro University of Science and
Technology P.O. Box 190-50100, Kakamega, Kenya

\author{
Article History \\ Received: 21.01.2021 \\ Accepted: 05.03.2021 \\ Published: 06.04.2021 \\ Journal homepage:
}

https://www.easpublisher.com

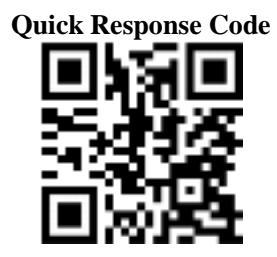

Abstract: Among patients with symptoms suggestive of a Urinary tract infection (UTI) which includes dysuria and frequency, the diagnosis can be confirmed by sending a cleancatch specimen for culture and for urinalysis. One suggested exception recommended by most experts is a symptomatic young woman with pyuria detected by urinalysis dipstick who has apparently uncomplicated cystitis. It has been proposed that the findings are sufficiently diagnostic that an empiric course and usually three days of antimicrobial therapy can be initiated without performing a urine culture. Children who are toilet trained can provide clean voided urine samples. Clean voided bag urine samples are acceptable for urinalysis in infants and children between two months and two years of age who have unexplained fever and do not appear ill enough to require immediate antimicrobial therapy. If the sample suggests infection, then a catheterized urine specimen should be obtained for confirmatory testing and urine culture. Suprapubic aspiration and transurethral bladder catheterization are invasive but are the only valid ways to collect urine for culture in febrile young infants under two months of age and older infants and children with unexplained fever who are younger than two years of age and ill enough to merit immediate antimicrobial therapy. The use of portable ultrasound to visualize the bladder increases the success rate for both suprapubic aspiration and transurethral bladder catheterization. In this review article, we will cover urine sampling, procedure, culture, and dipstick as a tool of UTI analysis in both adults and children.

Keywords: Urine Sampling, Diagnosis, Tract Infection.

Copyright (C) 2021 The Author(s): This is an open-access article distributed under the terms of the Creative Commons Attribution 4.0 International License (CC BY-NC 4.0) which permits unrestricted use, distribution, and reproduction in any medium for non-commercial use provided the original author and source are credited.

\section{INTRODUCTION}

Urine collected in a normal individual by suprapubic aspiration of the bladder is sterile and does not contain leukocytes. This method represents the gold standard in the diagnosis of urinary tract infection (UTI) [1]. It is, however, not performed routinely in clinical practice in which urine samples are generally obtained after natural micturition; in this setting, some degree of artifactual contamination with normal urethral organisms must be accepted.

Among patients with symptoms suggestive of a UTI, the diagnosis can be confirmed by sending a clean-catch specimen for culture and for urinalysis. One suggested exception recommended by most experts is a symptomatic young woman with pyuria (detected by urinalysis or dipstick) who has apparently uncomplicated cystitis. It has been proposed that this constellation of findings is sufficiently diagnostic that an empiric course (usually three days) of antimicrobial therapy can be initiated without performing a urine culture [2]. The choice of antibiotic is generally determined by the local susceptibility patterns of Escherichia coli, the usual causative organism, and a patient history of antibiotic allergy, especially to sulfonamides. Below are the indications for cultures in young women are:

- Suspicion of a complicated infection

- Atypical symptoms

- Failure to respond to initial therapy, raising the possibility of a resistant organism

- Recurrent symptoms less than one month after treatment of a previous UTI for which no culture was performed

In children, Urinary tract infections (UTIs) are an important cause of acute and chronic morbidity. Long-term complications include hypertension and decreased renal function caused by renal scarring. However this may not be suspected by the paeditricians. The accurate diagnosis of UTI in children is necessary to ensure appropriate therapy and follow-up for those who need it, and to avoid unnecessary therapy, hospital admission, and further evaluation in those who do not. 
The manner in which urine is collected and processed before it is cultured can affect the validity of the culture result. Children who are toilet trained can provide clean voided urine samples. Samples of urine from children who are not toilet trained can be obtained by "clean voided" bag samples, suprapubic bladder aspiration (SPA), or transurethral bladder catheterization (TUBC). SPA and TUBC are invasive but are the only valid ways to collect urine for culture in febrile young infants under two months of age and older infants and children with unexplained fever who are younger than two years of age and ill enough to merit immediate antimicrobial therapy [1].

\section{Urine sampling}

The likelihood of detecting a urethral tract infection (UTI) by urine culture is highest if urine is collected on arising. This sample is likely to be most concentrated and bacteria in the bladder will have had time to multiply overnight. However, getting an ideal sample is not practical since most cultures are obtained at the time the patient is seeing the clinician. In this setting, the combination of a more dilute urine and partial bacterial washout due to multiple voids may lower the colony count below the accepted definition for a UTI.

The following steps should be performed to minimize the degree of bacterial contamination.

- Local disinfection of the meatus and adjacent mucosa should be performed with a nonfoaming antiseptic solution; this region should then be dried with a sterile swab to avoid mixture of the antiseptic with urine.

- Contact of the urinary stream with the mucosa should be minimized by spreading the labia in females and by pulling back the foreskin in uncircumcised males.

- The first voided specimen should be discarded since the initial urine flushes urethral contaminants. It is the second, midstream sample that should be sent to the laboratory.

- Evaluation of the last few drops of urine is indicated after prostatic massage in men with suspected prostatitis. Firm prostatic massage per rectum, from lateral to midline on each side, causes the contents of the prostatic ducts to be expressed; vertical strokes in the midline will then project the secretions into the urethra and permit counting of leukocytes.

- The urine sample should be sent immediately to the bacteriology laboratory since bacteria will continue to proliferate in the warm medium of freshly voided urine, leading to increased bacterial counts. If such immediate referral is not possible, the container should be transported in iced water and then stored in a refrigerator at $4^{\circ} \mathrm{C}$. Cooling stops bacterial growth, but the following day the bacteria can still grow on culture medium. However, urinary leukocytes may be altered by refrigeration, possibly affecting interpretation of the urinalysis.

\section{A positive urine culture}

The standard definition of a positive urine culture is $\geq 10^{5} \mathrm{CFU} / \mathrm{mL}$ together with pyuria (eg, leukocyte count $\geq 10^{5} \mathrm{WBC} / \mathrm{mL}$ ). Normal values in a noninfected midstream, clean-catch sample are $<10^{5}$ colony-forming units (CFU, primarily due to contaminating Escherichia coli) and $<10,000$ leukocytes per $\mathrm{mL}$ of urine [3-7]. Contamination in the absence of UTI is typically suggested by high CFU counts without significant leukocyturia in a patient with no urinary tract symptoms such dysuria, frequency or fever.

However, this definition does not apply to all patients. If fecal contamination has been ruled out, a lower colony count $\left(>10^{2} / \mathrm{mL}\right)$ may be indicative of UTI. This was best demonstrated in studies in women who had dysuria and frequency but a midstream culture contained less $10{ }^{5} \mathrm{CFU} / \mathrm{mL}[1,8,9]$. This condition had been called the acute urethral syndrome [1]. In one study, for example, 42 such women (most of whom had $\geq 10^{2} \mathrm{CFU} / \mathrm{mL}$ on culture of a midstream specimen) who also had pyuria underwent suprapubic bladder aspiration. Thirty seven had a positive aspirate culture: 24 E. coli, 3 Staphylococcus saprophyticus, and 10 Chlamydia [1]. All of these women responded to appropriate antimicrobial therapy. In comparison, a positive culture was very uncommon in women with similar symptoms but no pyuria.

Similar findings have been reported by others. In a gynecology clinic at a student health center, for example, 33 percent of women with urinary tract symptoms had $\geq 10^{5} \mathrm{CFU} / \mathrm{mL}$ while another 46 percent had CFU counts between $10^{2}$ and $10^{4} / \mathrm{mL}$ [10]. When asymptomatic patients were included, there was a stepwise relation between the colony count and the likelihood of symptoms.

On the basis of these findings, it has been suggested that a CFU count $\geq 10^{2} / \mathrm{mL}$ be considered positive on a midstream urine specimen in women with acute symptoms and pyuria. It has been estimated that 88 percent of such women have a UTI [8]. If symptoms persist and the standard bacterial culture is negative, a pelvic examination should be performed with culture of a cervical swab for Chlamydia.

It is not well understood why some infected women have low colony counts. Two possibilities are that low counts reflect an earlier stage of infection and that low counts reflect the efficacy of bladder washout during urination to eliminate the organisms. 
There are also several other settings in which a colony count of $\leq 10^{5} / \mathrm{mL}$ often represents true infection rather than contamination:

- In patients already being treated with antimicrobials.

- In men in whom contamination is a much lesser problem.
- When organisms other than E. coli and Proteus are present. Included in this group are Pseudomonas, Klebsiella-EnterobacterSerratia, and Moraxella species, particularly in symptomatic patients with an indwelling bladder catheter.



Fig-1a: A negative urine culture

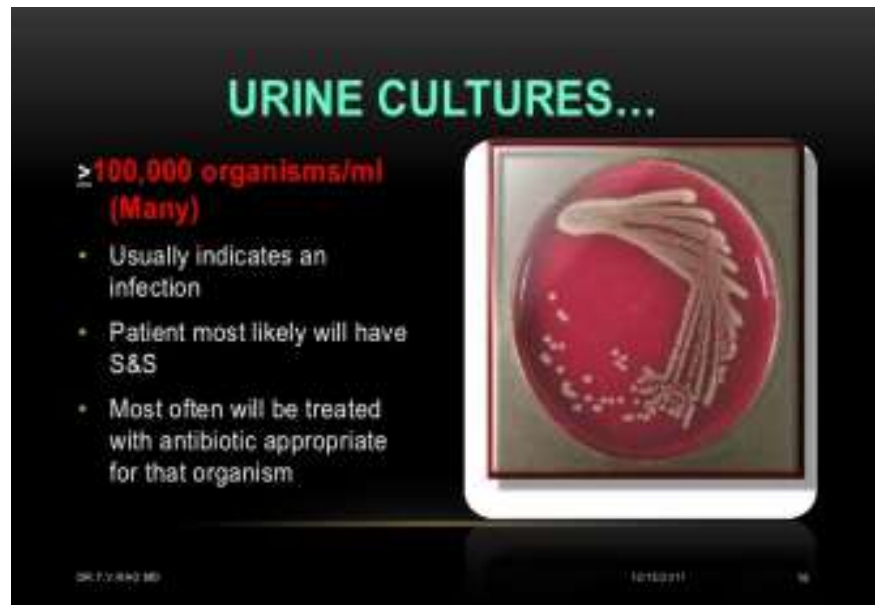

Fig-1b: A positive urine culture

\section{Pyuria}

Pyuria is defined as $>20,000$ leukocytes $/ \mathrm{mL}$ (by hemocytometry) in women with low count bacteriuria [10]. Others have defined pyuria as the presence of at least 8000 leukocytes per $\mathrm{mL}$ of uncentrifuged urine, which corresponds to 2 to 5 leukocytes per high power field in centrifuged sediment [1].

Given the very high association between infection and pyuria, a careful examination of the urine sediment is indicated in all patients with suspected UTI. However, assessment of pyuria is subject to some technical pitfalls [9]. Two important variables are contamination with vaginal secretions in women and the volume of supernatant in which the centrifuged pellet is resuspended, which will affect the leukocyte count.
These observations indicate that the customary determination of leukocyte counts per high-power field is not sufficiently accurate and that the use of white cell counting is preferred in the diagnosis of UTI. A significant number of leukocytes $(>10 / \mathrm{microL}$ or $10,000 / \mathrm{mL}$ ) should be present in truly infected patients. The presence of bacteria in the absence of pyuria, especially when various strains are found, is usually due to contamination during sampling.

\section{Sterile pyuria}

Whereas true infection without pyuria is unusual, pyuria can occur in the absence of apparent bacterial infection, particularly in patients who have already taken antimicrobials (often due to selfmedication). Other causes of sterile pyuria include: 
- Contamination of the urine sample by sterilizing solution

- Contamination of the urine sample with vaginal leukocytes

- Chronic interstitial nephritis

- Nephrolithiasis

- Uroepithelial tumor

- Painful bladder syndrome/interstitial cystitis

In the case of uroepithelial tumors, both malignant cells and leukocytes are shed [11]. The tumor can cause inflammation those results in the appearance or exacerbation of sterile pyuria. Malignant cells are difficult to distinguish from leukocytes on routine urinalysis. When the more common causes of sterile pyuria have been eliminated, patients with dysuria and frequency should be tested for atypical organisms such as Chlamydia, Ureaplasma urealyticum, or tuberculosis $[1,12]$.

\section{Dipsticks}

Dipsticks may be used as a screening tool for diagnosis of UTI; they detect the presence of leukocyte esterase and nitrite in the urine. The dipstick nitrite test depends on the conversion of nitrate (from dietary metabolites) to nitrite by bacteria in the urine; normally no detectable nitrite is present. When bacteriuria is significant, the test is positive about 80 percent of cases in which the urine has incubated for at least four hours in the bladder [13]. Leukocyte esterase corresponds to pyuria and nitrite reflects the presence of Enterobacteriaceae, which convert urinary nitrate to nitrite $[14,15]$. In one study, dipstick was comparable to urinalysis for UTI screening; both had high false positive and false negative rates [16]. A negative dipstick in a patient with symptoms of UTI may represent false negative results, and a urine culture should be performed [17].

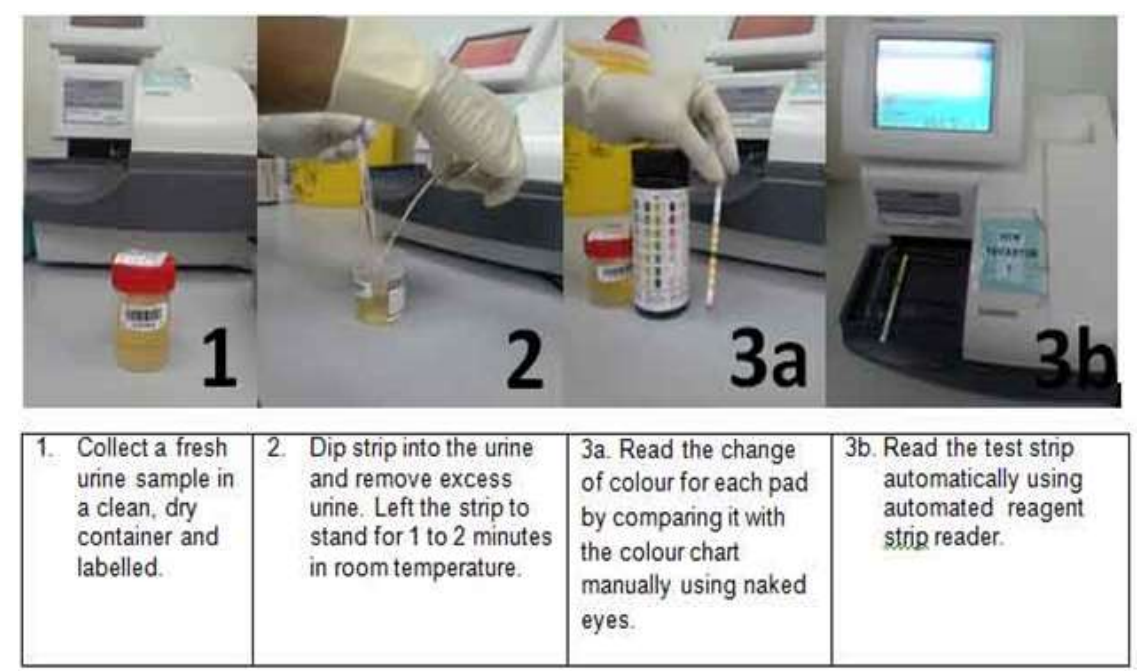

Fig-2a: Procedure for urine dipstick test

Results are in qualitative and semiquantitative. The test strip that has been dip into the urine will change in color. Than the colour produce in the strip need to be compare with colour chart as below in figure $2 b$. 


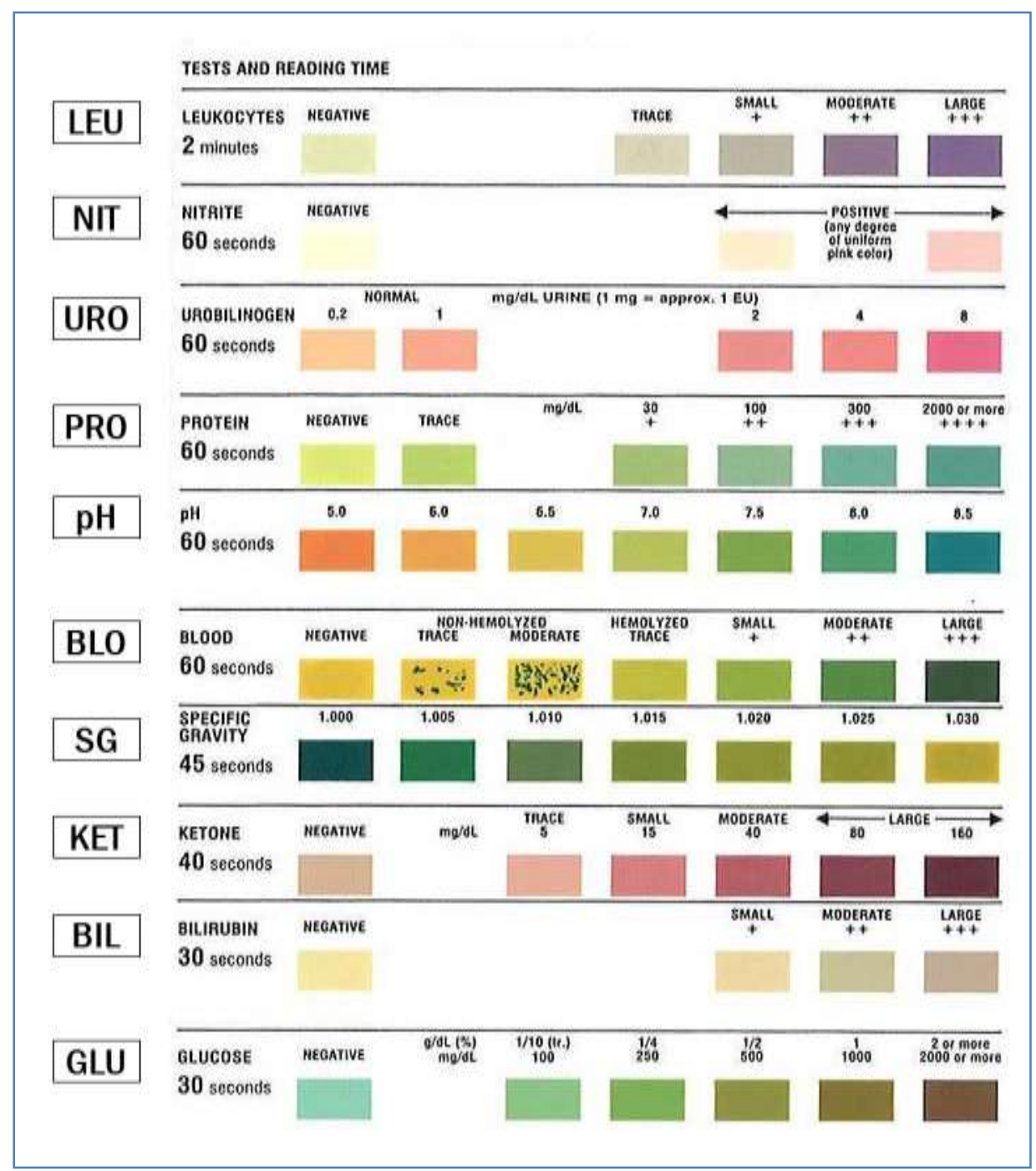

Fig-2b: (Chart 1 - Colour chart provided by the manufacturer: Source Siemens Multistix 10 SG)

In a review of six studies including women aged 17 to 70 with suspected UTI in primary care settings; positive dipstick findings (nitrite or leukocyte esterase and blood) had sensitivity and specificity of 75 and 66 percent, respectively [18]. A meta-analysis including 70 publications noted concluded that urine dipstick test alone is useful when both nitrite and leukocyte esterase tests are negative (sensitivity 68 to 88 percent) [19]. A systematic review including 30 studies noted that a positive leukocyte esterase or nitrite test had the highest sensitivity and the lowest negative likelihood ratio [20]. Subsequent studies reveal fewer positive results of the dipstick test. A total of 434 adult females with suspected lower UTI in a primary care setting were assessed. Presence of blood was a criterion added to the nitrite and leukocyte esterase tests. Sixtysix patients had confirmed UTI. Clinical criteria (urine cloudiness, dysuria and nocturia) were also taken into account. The negative predictive value was 67 percent for none of the features, and the positive value was 82 percent for three features. The authors concluded that dipstick results can modestly improve, but poorly rule out infection [21]. Among 2252 women with overactive bladder, dipstick test was not sufficient to identify patients with UTI (sensitivity and specificity 44 and 86 percent, respectively) $[22,23]$. Thus, a positive test is a reliable index of significant bacteriuria, though a negative test does not exclude bacteriuria. Reasons for a negative nitrite test in the presence of bacteriuria include insufficient bladder incubation time for conversion of nitrate to nitrite, low urinary excretion of nitrate, inability of some organisms to convert nitrate to nitrite such as E. faecalis and decreased urine $\mathrm{pH}$ due to cranberry juice or other dietary supplements. 


\begin{tabular}{|c|c|c|c|}
\hline Parameter & $\begin{array}{l}\text { Normal } \\
\text { reference } \\
\text { range }\end{array}$ & $\begin{array}{l}\text { Influence factor such diet and environment that interfere } \\
\text { results } \\
\text { (Limit of detection) } \\
\text { Description for False Positive and False Negative: } \\
\text { Results from the strip shown positive or negative (nil) but } \\
\text { not caused by the organ problem. }\end{array}$ & Clinical significance \\
\hline Blood & Negative & $\begin{array}{l}\text { False Positive: Taking any food that can colour the urine or } \\
\text { having menstrual. Urine exposed to hypochlorite as chlorox. } \\
\text { False Negative: Taking Vitamin C (ascorbic acid) }\end{array}$ & $\begin{array}{ll}\text { 1. } & \begin{array}{l}\text { Hematuria } \\
\text { (nephritis,trauma) }\end{array} \\
\text { 2. } & \text { Myoglobinuria } \\
\end{array}$ \\
\hline Bilirubin & Negative & $\begin{array}{l}\text { False Positive: Taking medicine such as chlorpromazine or } \\
\text { phenazopyridine. } \\
\text { False Negative: Taking Vitamin C (ascorbic acid). Urine } \\
\text { exposed to sunlight or lamp. }\end{array}$ & $\begin{array}{l}\text { 1. Liver diseases as } \\
\text { hepatitis } \\
\text { 2. Jaundice }\end{array}$ \\
\hline Urobilinogen & $\begin{array}{l}3.2-16 \\
\mathrm{umol} / \mathrm{L}\end{array}$ & $\begin{array}{l}\text { False Positive: Urine contaminated with p-aminobenzoic } \\
\text { acid. } \\
\text { False Negative: Urine exposed to sunlight or lamp. }\end{array}$ & $\begin{array}{ll}\text { 1. } & \begin{array}{l}\text { Liver diseases as } \\
\text { cirrhosis }\end{array} \\
\text { 2. } & \text { Hemolytic anemia } \\
\end{array}$ \\
\hline Ketone & Negative & $\begin{array}{l}\text { False Positive: Taking low carbohydrate such as wheat or } \\
\text { rice, vomit or diarrhoea'. Urine exposed to moisture too long. } \\
\text { Taking medicine such as MESNA and captopril. }\end{array}$ & $\begin{array}{ll}\text { 1. } & \text { Ketonuria } \\
\text { 2. } & \text { Diabetic } \\
& \text { Ketoacidosis } \\
\text { 3. } & \text { Prolonged fasting } \\
\end{array}$ \\
\hline Protein & $\begin{array}{l}\text { Negative dan } \\
\text { Trace } \\
(<0.15 \mathrm{~g} / \mathrm{L})\end{array}$ & $\begin{array}{l}\text { False Positive: Extreme exercise, dehydrated, taking high } \\
\text { protein or emotional stress. Urine exposed to hypochlorite as } \\
\text { chlorox or blood. }\end{array}$ & $\begin{array}{ll}\text { 1. } & \text { Fever } \\
\text { 2. } & \text { Proteinuria } \\
\text { 3. } & \text { Kidney disease } \\
\text { 4. } & \text { Nephrotic syndrome } \\
\end{array}$ \\
\hline Nitrite & Negative & $\begin{array}{l}\text { False Positive: Urine exposed to room temperature more } \\
\text { than } 2 \text { hours. } \\
\text { False Negative: Taking Vitamin C (ascorbic acid). Collect } \\
\text { urine so early (less bacteria incubation period in bladder). }\end{array}$ & Urinary Tract Infection \\
\hline Glucose & Negative & $\begin{array}{l}\text { False Positive: Taking Vitamin C (ascorbic acid). } \\
\text { False Negative: Low glucose renal threshold and high } \\
\text { ketone. }\end{array}$ & $\begin{array}{ll}\text { 1. } & \text { Glucosuria } \\
\text { 2. } & \text { Diabetis mellitus } \\
\text { 3. } & \text { Renal glycosuria } \\
\end{array}$ \\
\hline $\mathrm{pH}$ & $\begin{array}{l}\text { pH5 hingga } \\
\text { pH7.5 }\end{array}$ & $\begin{array}{l}\text { More alkaline: Diets with a high content of vegetables and } \\
\text { citrus fruit.Vomit or starvation. Urine exposed to room } \\
\text { temperature for more than } 2 \text { hours. }\end{array}$ & $\begin{array}{ll}\text { 1. } & \text { Kidney stone } \\
\text { 2. } & \text { Metabolic acidosis } \\
\text { 3. } & \text { Renal tubular } \\
& \text { acidosis } \\
\end{array}$ \\
\hline $\begin{array}{l}\text { Specific } \\
\text { Gravity }\end{array}$ & $\begin{array}{l}1.002 \text { hingga } \\
1.030\end{array}$ & $\begin{array}{l}\text { False Positive: Dehydrated diarrhoea or taking antibiotic or } \\
\text { diuretic medicines (substance that removes water from the } \\
\text { body by promoting urine formation and the loss of salt } \\
\text { (sodium). Urine exposed to room temperature for more than } \\
2 \text { hours. }\end{array}$ & Diabetis insipidus \\
\hline $\begin{array}{l}\text { Leukocyte } \\
\text { esterase }\end{array}$ & Negative & $\begin{array}{l}\text { False Positive: Urine exposed to Formalin or hypochlorite as } \\
\text { chlorox. Taking Vitamin C (ascorbic acid). High specific } \\
\text { gravity. } \\
\text { False Negative: Glucose level more than } 3 \mathrm{~g} / \mathrm{dL} \text {. Taking } \\
\text { antibiotic such as cephalexin, cephalotin and tetracycline. }\end{array}$ & $\begin{array}{ll}\text { 1. } & \text { Urinary Tract } \\
\text { Infection } \\
\text { 2. } \\
\text { 3. } & \text { Kidney } \\
\text { 4. } & \text { Acute inflame } \\
& \text { Renal calculus } \\
\end{array}$ \\
\hline
\end{tabular}

\section{In children}

\section{Clean voided bag samples}

The practice of obtaining urine specimens by the "clean voided" bag appeals to medical staff and parents because it is noninvasive. However, it should not be used to obtain urine samples for culture [24]. Appropriate collection of clean voided bag urine samples requires proper cleansing, rinsing, and drying of the perineum before application of the bag, immediate removal of the bag after urine is voided, and prompt processing of the urine. Cultures of urine specimens obtained by clean voided bag have an unacceptably high rate of false positive results compared with catheterized specimens [25-28]. As an example, in an observational study of 7584 children younger than two years) undergoing urine collection for culture, 63 percent of clean voided bag specimens were contaminated compared with 9 percent of catheter specimens (63 percent versus 9 percent [25]. An adverse outcome (delayed diagnosis and treatment, unnecessary recall, unnecessary treatment, unnecessary hospital admission, and/or unnecessary radiologic investigation) occurred in 132 of the 3440 children who had a false positive urine culture.

According to the guidelines of American Academy of Pediatrics Subcommittee on UTI, clean voided bag urine samples are acceptable for urinalysis in infants and children between two months and two years of age who have unexplained fever and do not appear ill enough to require immediate antimicrobial therapy. An infant or young child should never receive 
antibiotics on the basis of a urinalysis from a clean voided bag urine specimen. Thus, another urine sample for urinalysis and culture should be collected by invasive means if the urinalysis from the bag sample suggests a UTI by any of the following:

- Positive leukocyte esterase or nitrite test

- Greater than 5 white blood cells per highpower field (spun urine)

- Presence of bacteria on Gram stained urine (unspun urine)

Monitoring the clinical course of the infant or child without antibiotic therapy is a reasonable course of action if the urinalysis is not suggestive of UTI. However, a negative urinalysis does not exclude a UTI.

\section{Clean voided samples}

Children who are toilet trained can provide clean voided midstream urine samples. Cleansing the perineum with soap prior to urine collection may decrease the rate of contamination [29].

We suggest using the following technique to collect urine samples:

- For girls, the labia should be spread and the perineum cleansed two to three times with nonfoaming antiseptic solution or mild soap. For boys, the meatus should be cleansed in a similar fashion. The foreskin should be retracted before cleansing for those who are uncircumcised.

- Contact of the urinary stream with the mucosa can be minimized by pulling back the foreskin in boys who are uncircumcised and by spreading the labia in girls during urination.

- The child should urinate into a toilet or urinal. Midway through urination, a specimen should be collected in a sterile container.

\section{Suprapubic bladder aspiration (spa)}

Suprapubic bladder aspiration is a safe and effective method for obtaining urine specimens in infants and young children (usually not performed in children who are older than two years). The distended bladder, which extends above the level of the pubic symphysis into the lower abdomen, is easy to access percutaneously. Success is more likely if the bladder can be visualized by portable ultrasonography, percussed, or palpated and the child has not emptied the bladder in the 60 minutes before the procedure $[30,31]$. Percussion or palpation of the bladder may stimulate urination in some children. This method represents the gold standard in the diagnosis of UTI [32-34]. In one study, clean voided bag, clean voided, and SPA urine samples were obtained on the same day from thirty hospitalized children between the ages of one day and three years [34]. Compared with the other collection methods, SPA yielded no cultures with mixed growth or colony count less than 10,000 per $\mathrm{mL} /$ urine, suggestive of contamination ( 0 versus 73 percent for mixed growth from both bag and clean voided samples; and 0 versus 6 percent and 13 percent for intermediate growth from clean voided and bag samples, respectively).

\section{The following steps are performed $[35,36]$}

- The child is restrained in the supine and frog leg position. This position permits adequate stabilization of the pelvis.

- The site for needle insertion, in the midline, approximately one to two centimeters above the pubic symphysis, is widely prepared with povidone-iodine solution.

- The planned puncture site may be locally anesthetized with lidocaine. Many practitioners do not perform this step because they believe it is more painful than the procedure itself.

- The urethral opening should be occluded just before needle insertion because the procedure will stimulate urination in many children. This is accomplished by squeezing the penile urethra in boys or applying urethral pressure to the meatus in girls [35].

- A 1.5 inch, 22-gauge needle attached to a 3 or $5 \mathrm{~mL}$ syringe is inserted one to two centimeters above the pubic symphysis. The needle should be angled 10 to 20 degrees cephalad and advanced under negative pressure until urine returns. The needle should be partially withdrawn and redirected at an angle more perpendicular to the frontal plane if the initial attempt is unsuccessful.

Urine is not likely to be obtained after the third attempt and thus, one can either perform transurethral bladder catheterization or wait 15 to 30 minutes for the bladder to become more distended [36].

\section{Portable ultrasound}

Portable ultrasound (US) is becoming increasingly available in the emergency department and helps to improve the success rate of obtaining urine with SPA. In a randomized study of 66 patients, the success rate with US was 79 percent (versus 52 percent without US) [37].

\section{Complications}

Minor complications, such as microscopic hematuria, are common. Major complications, such as gross hematuria [38, 39] and anterior abdominal wall abscess, are rare [40]. Intestinal perforation can occur if a loop of bowel overlies the bladder, but the small puncture rarely leads to peritonitis [41]. Intestinal (or other viscus) perforation can be avoided if the procedure is not performed in children who have abdominal distension, organomegaly, volume depletion, or congenital anomalies of the gastrointestinal or genitourinary tract [41]. 


\section{Transurethral bladder catheterization (tubc)}

The catheterization of the urethra is another safe and effective method for obtaining urine samples for culture in most infants and children who are not toilet trained. Specimen contamination may occur in up to 15 percent of children under two years of age and is more common in uncircumcised boys, infants under six months of age, and children in whom the urethra is not well visualized or who require several attempts to pass the catheter [42]. An explanation of the anatomy and the indications for the procedure should be given to parents and caregivers before transurethral bladder catheterization is performed to avoid unnecessary parental anxiety about the manipulation of their child's genitals. In addition, whether the child has latex allergy must be determined because the condition is common in children with spina bifida and other conditions that require frequent bladder catheterization.

\section{The following steps are performed}

- The child is restrained in the supine and frog leg position. This position permits adequate stabilization of the pelvis and complete visualization of the external genitalia.

- The anterior urethra is cleansed thoroughly with povidone-iodine solution.

- A sterile lubricant jelly is applied to the end of an appropriately sized catheter (5 French for children younger than six months; 8 French for those between six months and adolescence, and 10 French for adolescents).

The efficacy of using topical lidocaine to reduce pain during urethral catheterization in children is uncertain. In one randomized trial, children who were catheterized using a lubricant containing lidocaine experienced less pain during the procedure [43]. In a similar report in infants, however, there was no difference in pain scores with and without topical lidocaine [44]. If a topical anesthetic is used, it should be applied two to three minutes before the procedure is performed.

\section{Boys}

- The foreskin of the glans is retracted gently to permit complete visualization of the urethral meatus if the boy is uncircumcised. The foreskin must be repositioned after the procedure to prevent paraphimosis.

- The urethra is straightened by using the nondominant hand to hold the penis perpendicular to the lower abdomen. Gentle traction is applied.

- The catheter is inserted with the dominant hand until urine returns.

- As the catheter is being advanced, it can be palpated along the posterior aspect of the penis. Resistance may be encountered near the base of the penis due to contraction of the external bladder sphincter. This can generally be overcome by maintaining traction on the penis, while applying gentle pressure with the catheter. The catheter should never be forced

\section{Girls}

- The urethra may be difficult to visualize in girls. An assistant often is needed to retract the labia majora. In addition, redundant tissue around the introitus can sometimes obscure the urethral meatus. Swabbing the area from front to back may push this tissue out of the way and permit the povidine-iodine solution to pool in the meatus, making it easier to identify.

- The catheter is inserted into the urethral meatus until urine returns. Catheters that are inadvertently placed in the vagina may be left in place to serve as a landmark for subsequent attempts.

- The first few drops of urine obtained should be discarded to prevent contamination of the urine with urethral organisms or cells. A prospective study comparing early and later urine samples obtained by TUBC in 86 children demonstrated that inclusion of the early stream urine increases false positive results on urinalysis for white blood cell counts and bacteria detection [45].

\section{Portable ultrasound}

Portable ultrasound (US) is increasingly available in the emergency department and helps to improve the success rate of obtaining urine with TUBC. In a prospective study, the success rate for obtaining urine on the first attempt with US was 96 percent (versus 72 percent without US) [46].

\section{Complications}

Complications of bladder catheterization are minimal and include urethral trauma and microscopic hematuria. In addition, catheterization can cause iatrogenic infection. However, this risk was assessed by the AAP subcommittee on UTI and found to be extremely low, and no change was made in the recommendation to perform the procedure.

\section{Comparison of suprapubic bladder aspiration and transurethral bladder catheterization}

Few studies have compared suprapubic bladder aspiration and urethral catheterization in infants and children:

- One hundred infants younger than six months of age who were being evaluated for febrile illness, suspected UTI, or sepsis were randomly assigned to undergo SPA or TUBC. TUBC was more successful (100 versus 46 percent) but took more time (mean time of 81 versus 17 seconds) than did SPA [31]. In 
addition, TUBC was 100 percent successful after failed SPA.

- Thirty-three neonates who required sterile collection of urine were randomly assigned to urine collection by SPA or TUBC [46]. TUBC was more successful ( 81 versus 65 percent), but the volume of urine obtained was insufficient for analysis more often (69 versus 41 percent).

- Urine samples from 42 children, aged three months to 10 years, were obtained by SPA and TUBC after elective surgery. TUBC samples were divided into first and second portions [33]. Sterile cultures were obtained more often from SPA than from second TUBC sample, and more often from second than from first TUBC sample (95 versus 80 versus 60 percent). When cultures with nonpathogenic organisms or colony counts less than 10.000 per mL/urine were assumed to be contaminated, the agreement between SPA and TUBC for "sterility" was 98 percent for the second portion and 93 percent for the first.

\section{Processing of urine samples}

The urine sample should be sent immediately to the bacteriology laboratory because bacteria will continue to proliferate in the warm medium of freshly voided urine, leading to increased bacterial counts. If such immediate dispatch is not possible, the container should be transported in iced water and then stored in a refrigerator at $4^{\circ} \mathrm{C}$. Cooling stops bacterial growth until the urine is plated on culture medium and incubated. However, urinary leukocytes may be altered by refrigeration, possibly affecting interpretation of the urinalysis.

\section{CONCLUSION}

Among patients with symptoms suggestive of a UTI (dysuria and frequency), the diagnosis can be confirmed by sending a clean-catch specimen for culture and for urinalysis. The collection of findings is sufficiently diagnostic that an empiric course (usually three days) of antimicrobial therapy can be initiated without performing a urine culture. The indications for culture in young women are: Suspicion of a complicated infection, Atypical symptoms, Failure to respond to initial therapy, raising the possibility of a resistant organism and Recurrent symptoms less than one month after treatment of a previous UTI for which no culture was performed The standard definition of a positive urine culture is $\geq 10^{5} \mathrm{CFU} / \mathrm{mL}$ together with pyuria (eg, leukocyte count $\geq 10^{5} \mathrm{WBC} / \mathrm{mL}$ ). Other causes of sterile pyuria include: Contamination of the urine sample by sterilizing solution, Contamination of the urine sample with vaginal leukocytes, chronic interstitial nephritis and Nephrolithiasis. For screening purposes, dipsticks may be used as a screening tool for diagnosis of UTI; normally, no detectable nitrite is present. When bacteriuria is significant, the test is positive about 80 percent of cases in which the urine has incubated for at least four hours in the bladder. Leukocyte esterase corresponds to pyuria and nitrite reflects the presence of Enterobacteriaceae, which convert urinary nitrate to nitrite.

\section{RECOMMENDATION}

Among patients with symptoms suggestive of a UTI (dysuria and frequency), the diagnosis can be confirmed by sending a clean-catch specimen for culture and for urinalysis. One suggested exception recommended by most experts is a symptomatic young woman with pyuria (detected by urinalysis or dipstick) who has apparently uncomplicated cystitis. It has been recommended that a CFU count $\geq 10^{2} / \mathrm{mL}$ be considered positive on a midstream urine specimen in women with acute symptoms and pyuria whereas true infection without pyuria is unusual, pyuria can occur in the absence of apparent bacterial infection, particularly in patients who have already taken antimicrobials most often due to self-medication. It is important to note that in Uroepithelial tumor when the more common causes of sterile pyuria have been eliminated, patients with dysuria and frequency should be tested for atypical organisms, such as Chlamydia, Ureaplasma urealyticum, or tuberculosis.

\section{REFERENCES}

1. Stamm, W. E., Wagner, K. F., Amsel, R., Alexander, E. R., Turck, M., Counts, G. W., \& Holmes, K. K. (1980). Causes of the acute urethral syndrome in women. New England Journal of Medicine, 303(8), 409-415.

2. Wilson, M. L., \& Gaido, L. (2004). Laboratory diagnosis of urinary tract infections in adult patients. Clinical infectious diseases, 38(8), 11501158.

3. Kass, E. H. (2002). Asymptomatic infections of the urinary tract. The Journal of urology, 167(2), 10161020.

4. Platt, R. (1983). Quantitative definition of bacteriuria. The American journal of medicine, 75(1), 44-52.

5. Pollock, H. M. (1983). Laboratory techniques for detection of urinary tract infection and assessment of value. The American journal of medicine, 75(1), 79-84.

6. Sanford, J. P., Favour, C. B., Mao, F. H., \& Harrison, J. H. (1956). Evaluation of the "positive" urine culture: An approach to the differentiation of significant bacteria from contaminants. The American journal of medicine, 20(1), 88-93.

7. Tapsall, J. W., Bfll, S. M., Taylor, P. C., \& Smith, D. D. (1975). Relevance of" significant bacteriuria" to aetiology and diagnosis of urinary-tract infection. The Lancet, 306(7936), 637-639. 
8. Stamm, W. E., Counts, G. W., Running, K. R., Fihn, S., Turck, M., \& Holmes, K. K. (1982). Diagnosis of coliform infection in acutely dysuric women. New England Journal of Medicine, 307(8), 463-468.

9. Komaroff, A.L. (1984). Acute dysuria in women. $N$ Engl J Med; 310:368.

10. Kunin, C. M., Van Arsdale White, L., \& Hua Hua, T. (1993). A reassessment of the importance of low-count bacteriuria in young women with acute urinary symptoms. Annals of internal medicine, 119(6), 454-460.

11. Eagan, J.W. (1989). Urinary tract cytology. In: Uropathology, Hill GS (Ed), Churchill Livingstone, Philadelphia, 2, 873.

12. McDonald, M. I., Lam, M. H., Birch, D. E., D'arcy, A. F., Fairley, K. F., \& Pavillard, E. R. J. (1982). Ureaplasma urealyticum in patients with acute symptoms of urinary tract infection. The Journal of urology, 128(3), 517-519.

13. Williams, G. J., Macaskill, P., Chan, S. F., Turner, R. M., Hodson, E., \& Craig, J. C. (2010). Absolute and relative accuracy of rapid urine tests for urinary tract infection in children: a metaanalysis. The Lancet infectious diseases, 10(4), 240-250.

14. McNEELEY, S. G., Baselski, V. S., \& Ryan, G. M. (1987). An evaluation of two rapid bacteriuria screening procedures. Obstetrics and gynecology, 69(4), 550-553.

15. Pfaller, M. A., \& Koontz, F. P. (1985). Laboratory evaluation of leukocyte esterase and nitrite tests for the detection of bacteriuria. Journal of clinical microbiology, 21(5), 840-842.

16. Lammers, R. L., Gibson, S., Kovacs, D., Sears, W., \& Strachan, G. (2001). Comparison of test characteristics of urine dipstick and urinalysis at various test cutoff points. Annals of emergency medicine, 38(5), 505-512.

17. Koeijers, J. J., Kessels, A. G., Nys, S., Bartelds, A., Donker, G., Stobberingh, E. E., \& Verbon, A. (2007). Evaluation of the nitrite and leukocyte esterase activity tests for the diagnosis of acute symptomatic urinary tract infection in men. Clinical infectious diseases, 45(7), 894-896.

18. Little, P., Turner, S., Rumsby, K., Warner, G., Moore, M., Lowes, J. A., \& Mullee, M. (2009). Dipsticks and diagnostic algorithms in urinary tract infection: development and validation randomised trial, economic analysis, observational cohort and qualitative study. Health Technol Assess, 13(19), 173.

19. Devillé, W. L., Yzermans, J. C., Van Duijn, N. P., Bezemer, P. D., Van Der Windt, D. A., \& Bouter, L. M. (2004). The urine dipstick test useful to rule out infections. A meta-analysis of the accuracy. BMC urology, 4(1), 1-14.

20. St John, A., Boyd, J. C., Lowes, A. J., \& Price, C. P. (2006). The use of urinary dipstick tests to exclude urinary tract infection: a systematic review of the literature. American journal of clinical pathology, 126(3), 428.

21. Little, P., Rumsby, K., Jones, R., Warner, G., Moore, M., Lowes, J. A., \& Mullee, M. (2010). Validating the prediction of lower urinary tract infection in primary care: sensitivity and specificity of urinary dipsticks and clinical scores in women. British Journal of General Practice, 60(576), 495-500.

22. Hessdoerfer, E., Jundt, K., \& Peschers, U. (2011). Is a dipstick test sufficient to exclude urinary tract infection in women with overactive bladder?. International urogynecology journal, 22(2), 229-232.

23. Representatives, L. (1999). Practice parameter: the diagnosis, treatment, and evaluation of the initial urinary tract infection in febrile infants and young children. American Academy of Pediatrics. Committee on Quality Improvement. Subcommittee on Urinary Tract Infection. Pediatrics, 103(4), 843-52.

24. Al-Orifi, F., McGillivray, D., Tange, S., \& Kramer, M. S. (2000). Urine culture from bag specimens in young children: are the risks too high?. The Journal of pediatrics, 137(2), 221-226.

25. Tosif, S., Baker, A., Oakley, E., Donath, S., \& Babl, F. E. (2012). Contamination rates of different urine collection methods for the diagnosis of urinary tract infections in young children: an observational cohort study. Journal of paediatrics and child health, 48(8), 659-664.

26. Karacan, C., Erkek, N., Senel, S., Gunduz, S. A., Catli, G., \& Tavil, B. (2010). Evaluation of urine collection methods for the diagnosis of urinary tract infection in children. Medical Principles and Practice, 19(3), 188-191.

27. Vaillancourt, S., McGillivray, D., Zhang, X., \& Kramer, M. S. (2007). To clean or not to clean: effect on contamination rates in midstream urine collections in toilet-trained children. Pediatrics, 119(6), e1288-e1293.

28. Ruddy, R.M. (2006). Illustrated techniques of pediatric emergency procedures. In: Textbook of Pediatric Emergency Medicine, 5th, Fleisher GR, Ludwig S, Henretig FM. (Eds), Lippincott Williams \& Wilkins, Philadelphia, 1861.

29. Pollack Jr, C. V., Pollack, E. S., \& Andrew, M. E. (1994). Suprapubic bladder aspiration versus urethral catheterization in ill infants: success, efficiency, and complication rates. Annals of emergency medicine, 23(2), 225-230.

30. Stamm, W. E., Wagner, K. F., Amsel, R., Alexander, E. R., Turck, M., Counts, G. W., \& Holmes, K. K. (1980). Causes of the acute urethral syndrome in women. New England Journal of Medicine, 303(8), 409-415.

31. Pryles, C. V., Atkin, M. D., Morse, T. S., \& Welch, K. J. (1959). Comparative bacteriologic study of urine obtained from children by percutaneous 
suprapubic aspiration of the bladder and by catheter. Pediatrics, 24(6), 983-991.

32. Hardy, J. D., Furnell, P. M., \& Brumfitt, W. (1976). Comparison of sterile bag, clean catch and suprapubic aspiration in the diagnosis of urinary infection in early childhood. British journal of urology, 48(3), 279-283.

33. King, C., \& Henretig, F. M. (2000). Bladder catheterization and suprapubic bladder aspiration. Pocket Atlas of Pediatric Emergency Procedures, King, C, Henretig, FM (Eds), Lippincott Williams and Wilkins, Philadelphia, 257.

34. Nelson, J. D., \& Peters, P. C. (1965). Suprapubic aspiration of urine in premature and term infants. Pediatrics, 36(1), 132-134.

35. Hertz, A.L. (1997). Urinary tract infection. In: Pediatric Emergency Medicine Concepts and Clinical Practice, 2nd, Barkin R. (Ed), Mosby, St. Louis, 1164.

36. Gochman, R. F., Karasic, R. B., \& Heller, M. B. (1991). Use of portable ultrasound to assist urine collection by suprapubic aspiration. Annals of emergency medicine, 20(6), 631-635.

37. Carlson, K. P., \& Pullon, D. H. H. (1977). Bladder hemorrhage following transcutaneous bladder aspiration. Pediatrics, 60(5), 765-765.

38. Saccharow, L., \& Pryles, C. V. (1969). Further experience with the use of percutaneous suprapubic aspiration of the urinary bladder: Bacteriologic studies in 654 infants and children. Pediatrics, 43(6), 1018-1024.

39. Polnay, L., Fraser, A. M., \& Lewis, J. M. (1975). Complication of suprapubic bladder aspiration. Archives of disease in childhood, 50(1), 80-81.

40. Weathers, W. T., \& Wenzl, J. E. (1969). Suprapubic Aspiratior of the Bladder: Perforation of a Viscus Other Than the Bladder. American Journal of Diseases of Children, 117(5), 590-592.

41. Wingerter, S., \& Bachur, R. (2011). Risk factors for contamination of catheterized urine specimens in febrile children. Pediatric emergency care, 27(1), 1-4.

42. Gerard, L. L., Cooper, C. S., Duethman, K. S., Gordley, B. M., \& Kleiber, C. M. (2003). Effectiveness of lidocaine lubricant for discomfort during pediatric urethral catheterization. The Journal of urology, 170(2), 564-567.

43. Vaughan, M., Paton, E. A., Bush, A., \& Pershad, J. (2005). Does lidocaine gel alleviate the pain of bladder catheterization in young children? A randomized, controlled trial. Pediatrics, 116(4), 917-920.

44. Dayan, P. S., Chamberlain, J. M., Boenning, D., Adirim, T., Schor, J. A., \& Klein, B. L. (2000). A comparison of the initial to the later stream urine in children catheterized to evaluate for a urinary tract infection. Pediatric emergency care, 16(2), 88-90.

45. Chen, L., Hsiao, A. L., Moore, C. L., Dziura, J. D., \& Santucci, K. A. (2005). Utility of bedside bladder ultrasound before urethral catheterization in young children. Pediatrics, 115(1), 108-111.

46. Tobiansky, R., \& Evans, N. (1998). A randomized controlled trial of two methods for collection of sterile urine in neonates. Journal of paediatrics and child health, 34(5), 460-462.

Cite This Article: Iddah, M. Ali \& Benard O. Wesonga (2021). Urine Sampling and Culture in the Diagnosis of Urinary Tract Infection: A Review Article. East African Scholars J Med Surg, 3(4), 59-69. 